JPE 11-3-6

\title{
Novel SRM Drive Systems Using Variable DC-Link Voltage
}

\author{
Do-Hyun Jang ${ }^{\dagger}$ \\ $\dagger$ Dept. of Electrical Engineering, Hoseo University, Asan, Korea
}

\begin{abstract}
This paper proposes two SRM driving systems using a variable dc-link voltage controlled by a single-phase inverter. Two SRM converter topologies of a half bridge type and a full bridge type are proposed according to the power circuits of an inverter. The phase current can be controlled by means of a PWM controller at the inverter, and the turn-on/off angle at the phase switches can be controlled by a position sensor at the converter in the drive system. The inverter acts as a peak-current limiter if the transient current exceeds its maximum value. SRMs using the proposed topologies maintain high efficiency due to energy regeneration after the turn-off of power switches. The operational modes of the proposed topologies are verified by simulation and experimental results.
\end{abstract}

Key Words: PWM control, Single-phase inverter, Switched reluctance motor drives, Variable dc-link voltage

\section{INTRODUCTION}

The switched reluctance motor (SRM) is a promising candidate as a more economical and reliable alternative to the drives currently being used in industry. It has a simple and rugged construction, and its converter requires fewer power devices than induction motors or PM synchronous motor drives. The stator and rotor of an SRM have a doubly salient pole, and the rotor has no windings or magnets. The drive circuit of an SRM inherently protects against shocks caused by faults. Also, the current of each phase can be unidirectional. Unlike conventional inverter-fed induction machines, the cost and performance of an SRM drive is highly dependent on the converter topology used to drive the motor. Numerous different converter topologies have become popular for use in a variety of applications [1], [2].

The numerous SRM topologies can be classified into two types, namely the fixed dc-link and variable dc-link types, according to the performance of the dc-link voltage source, as shown in Fig. 1. Fig. 1(a) shows an ordinary SRM drive system using a fixed dc-link voltage source, which is directly supplied to the SRM converter. Most conventional SRM converter topologies belong to the fixed dc-link type [1], [2], and most of the SRM converter topologies proposed recently belong to the fixed dc-link type. In conventional SRM drive systems, current chopping is directly regulated by the phase switches. This increases the switching losses of the phase switches and it increases the motor core loss and acoustic noise during low-

\footnotetext{
Manuscript received Sep. 25, 2010; revised Feb. 19, 2011

Recommended for publication by Associate Editor Kyeong-Hwa Kim.

$\dagger$ Corresponding Author: jangdh@hoseo.edu

Tel: +82-41-540-5654, Fax: +82-41-540-5693, Hoseo University

Dept. of Electrical Engineering, Hoseo University, Korea
}

speed operation.

Fig. 1(b) shows a SRM drive system using a variable dc-link voltage source, in which a dc chopper is located between the fixed dc-link and the SRM drive. Recently, several researchers have been interested in SRM converter topologies using a variable dc-link voltage controlled by a dc chopper due to several advantages [3]-[11]. During low speed operation, the phase current is controlled by a PWM controller at the dc chopper, and the turn-on/off points at the phase switches can be regulated by a position sensor at the converter [11]. Moreover, this operation increases the power factor. However, the drive systems with the dc chopper have not been improved in spite of their advantages.

This paper proposes a normal SRM drive system using a variable dc-link voltage controlled by an inverter, as shown in Fig. 1(c). This figure shows that an inverter is located between a fixed dc-link and the SRM drive. This paper analyzes the operation modes of the proposed topologies, which are confirmed by simulation and experimental results.

\section{Proposed Basic Converter Topology}

Fig. 2 shows the proposed basic converter topology to realize the proposed drive system, as shown in Fig. 1(c). The basic converter topology requires one switch per phase and an ac voltage source with a pulse waveform. The power circuit of the proposed basic converter topology, neglecting the voltage source, is similar to that of a conventional split source converter as shown in Fig. 3. Therefore, the power circuit of the proposed topology with one switch per phase is simpler than any other topology. An "ac voltage source with pulse waveform" can be realized by a single-phase inverter. 


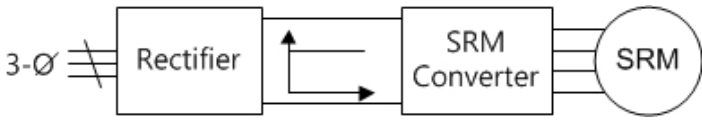

(a)

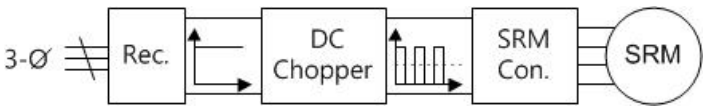

(b)

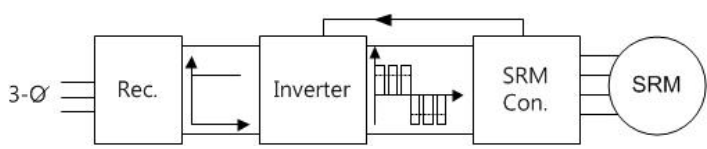

(c)

Fig. 1. (a) Conventional SRM drive system using a fixed dc-link voltage. (b) Conventional SRM drive system using a variable dc-link voltage controlled by a dc chopper. (c) Proposed drive system using a variable dc-link voltage controlled by an inverter.

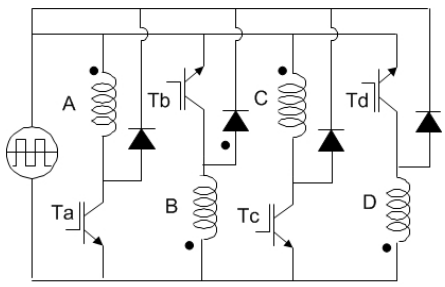

Fig. 2. Proposed basic converter topology for SRM drives $(n=4)$.

The complexity and manufacturing cost for the proposed system can be reduced because cheaper and simpler power switch modules or IPM (Intelligent Power Module) for an inverter have been recently developed. In this paper, two SRM converter topologies of a half bridge type and a full bridge type are proposed according to the single-phase inverter.

\section{Proposed CONVERTER TOPOlOGY Connected To a Single-Phase Half BRIDge INVERTER}

Fig. 4 shows the proposed SRM Converter connected to a single-phase Half Bridge Inverter (SCHBI). A half bridge inverter is composed of two switches and two capacitors with a midpoint. The half bridge inverter of a SCHBI supplies a twolevel voltage source $\left(V_{d c} / 2,-V_{d c} / 2\right)$ to the SRM converter.

The performance of the inverters in a SCHBI is different from those in ordinary single-phase bridge inverters. The single-phase bridge inverter in a SCHBI involves a regenerating pass, and the converter plays a role as a load for an inverter. The phase current can be controlled by a PWM controller at the inverter, and the turn-ON/OFF points can be regulated by a position sensor at the converter of the SCHBI. The proposed SCHBI has six basic operation modes as shown in Fig. 5.

\section{A. Operation Modes}

An SRM is singly excited and its torque is produced by the rotor's tendency to move toward the position where the inductance of the exciting stator pole winding is maximized. The linkage flux is a highly nonlinear function of the rotor position, and the flux path around the aligned position is

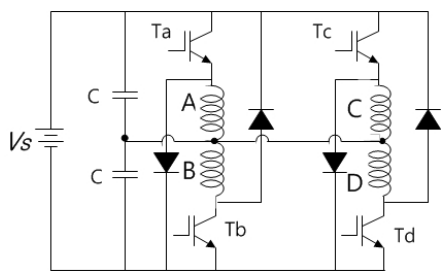

Fig. 3. Conventional split source converter topology.

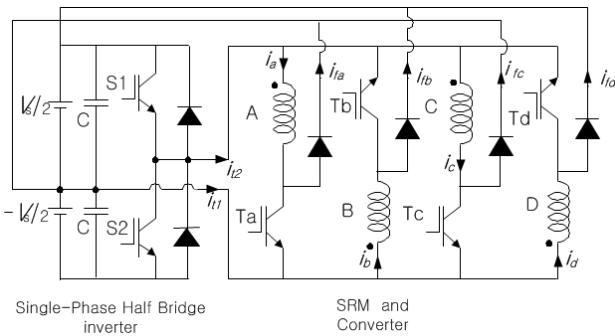

Fig. 4. The proposed SRM converter connected to a half bridge inverter (SCHBI; $n=4)$.

susceptible to saturation. The voltage equation for each phase $j$ to a phase is given by [1], [2], [13]:

$$
v(\theta)=i R_{a}+\frac{d \lambda_{j}(\theta, i)}{d t} .
$$

At a constant speed, the rate of change of the flux linkage is given by:

$$
\begin{aligned}
v(\theta) & =i R_{a}+\frac{d \lambda(\theta, i)}{d t}=i R_{a}+\frac{d\left\{L_{a}(\theta, i) i\right\}}{d t} \\
& =i R_{a}+L_{a}(\theta, i) \frac{d i}{d t}+\omega_{m} i \frac{d L_{a}(\theta, i)}{d \theta} \\
& =i R_{a}+L_{a}(\theta, i) \frac{d i}{d t}+e_{j}
\end{aligned}
$$

where $\lambda(\theta, i)\left(=L_{a}(\theta, i) i\right)$ is the flux linkage, $L_{a}(\theta, i)$ is the incremental inductance (the slope of the magnetization curve at the position $\theta), e_{j}$ is the back-emf, $\omega_{m}$ is the motor speed, and $R_{a}$ is the resistance per phase. Mode I, mode II, and mode III are related to phase winding A (or winding C), while mode IV, mode V, and mode VI are related to phase winding B (or winding D).

Mode I and mode IV (magnetizing period): Fig.5(a) shows mode $I$ when the phase switch $\mathrm{T}_{\mathrm{a}}$ is turned on, the inverter switch $S_{1}$ is $\mathrm{ON}$ and $\mathrm{S}_{2}$ is OFF. The energy of the dclink voltage $v(\theta)=V_{d c} / 2$ is transferred to the phase winding A (or winding $\mathrm{C}$ ). Assuming ideal devices, a constant speed, and linear magnetic characteristics, the phase current $i_{a 1}$ is obtained by solving (2) [2]:

$$
i_{a 1}(\theta)=\frac{V_{d c} / 2-e}{R_{a}}\left[1-\exp \left(\frac{-\theta}{\omega_{m} \tau_{1}}\right)\right]+I_{\theta\left(O N n_{n}\right)} \exp \left(\frac{-\theta}{\omega_{m} \tau_{1}}\right)
$$

$$
n=1,2,3, \ldots
$$

Where, $\tau_{1}=\frac{L_{a}(\theta, i)}{R_{e}}, e=\omega_{m} i \frac{d L_{i}(\theta, i)}{d \theta}$

where, $I_{\theta(O N n)}$ is the initial value of $i_{a 1}$ at $\omega t=\theta_{O N n}$, and it has the minimum value during the magnetizing period while $e$ is the back-emf. Fig. 5(e) shows mode IV when $\mathrm{T}_{\mathrm{b}}$ is turned on, $\mathrm{S}_{2}$ is $\mathrm{ON}$ and $\mathrm{S}_{1}$ is OFF. The energy of the dc-link voltage is transferred to the phase winding $\mathrm{B}$ (or winding $\mathrm{D}$ ). 
Mode II and mode V (first regenerating period): Fig. 5(b) shows mode II when $T_{a}$ is turned on and two inverter switches are OFF. The stored energy from the phase winding A (or winding $\mathrm{C}$ ) returns to the dc-link voltage through the inverter terminal. Therefore, the phase current $i_{a 2}$ decreases by the reverse dc-link voltage and is obtained by:

$$
i_{a 2}(\theta)=-\frac{V_{d c} / 2}{R_{e}}\left[1-\exp \left(\frac{-\theta}{\omega_{m} \tau_{1}}\right)\right]+I_{\theta(O F F n)} \exp \left(\frac{-\theta}{\omega_{m} \tau_{1}}\right)
$$

$$
n=1,2,3, \ldots
$$

where, $I_{\theta(O F F n)}$ is the initial value of $i_{a 2}$ at $\omega t=\theta_{O F F n}$, and it has the maximum value during the first regenerating period. Fig. 5(f) shows mode $V$ when $T_{b}$ is turned on, and $S_{1}$ and $S_{2}$ are OFF. This is the regenerating circuit for the phase winding B (or winding D), which is symmetrical to mode II.

Mode III and mode VI (second regenerating period): Fig. 5(c) shows mode III when $T_{a}$ is turned off and two inverter switches are OFF. The stored energy from the phase winding A (or winding $\mathrm{C}$ ) returns to the dc-link voltage through the regenerating path. The circuit of mode III is identical to the regenerating path of mode II. Therefore, the current tail $i_{a 3}$ is quickly suppressed by negative voltage $v(\theta)=-V_{d c} / 2$ after $\mathrm{T}_{\mathrm{a}}$ is turned off. This can be expressed by (4). Fig. 5(g) shows mode VI when $T_{b}$ is turned off and two inverter switches are OFF. The stored energy from the phase winding B (or winding D) returns to the dc-link voltage through the regenerating path. This is the regenerating circuit, which is symmetrical to mode III.

Overlapping mode: Fig. 5(d) shows the overlapping mode (between mode III and mode IV, or between mode VI and mode I) where the phase current flows simultaneously in the phase windings $\mathrm{A}$ and $\mathrm{B}$ (or windings $\mathrm{B}$ and $\mathrm{C}$, windings $\mathrm{C}$ and $\mathrm{D}$, or windings $\mathrm{D}$ and $\mathrm{A}$ ). When the off-going phase switch $\mathrm{T}_{\mathrm{b}}$ is turned on, the inverter switch $\mathrm{S}_{2}$ is $\mathrm{ON}$ at $\omega t=$ $\theta_{\text {ONn }}$ before the current tail is decayed. The energy of the dc-link voltage is transferred to the phase winding $\mathrm{B}$, and the stored energy from the phase winding A continues to return to the dc-link voltage. The signals and waveforms for a SCHBI according to the single-pulse method: (a) Switching signals to an inverter and to a converter. (b) Output voltage, output current at an inverter, phase voltage, and phase current at the phase windings.

The overlapping mode is omitted if mode IV begins after the current tail in mode III is decayed. Mode I \& mode IV (magnetizing period) and mode II \& mode $\mathbf{V}$ (first regenerating period) are used between the dwell angles $\left(\theta_{\text {on }}-\theta_{\text {off }}\right)$, but mode III \& mode VI (second regenerating period) and the overlapping mode are used during the second regenerating period after the turn-off of the phase switch.

\section{B. Waveforms}

Fig. 6 shows the switching signals and waveforms of the voltages and currents when a SCHBI operates with the PWM method using the hysteresis band at a low speed [12]. Two inverter switching signals $S_{1}$ and $S_{2}$ are controlled by a PWM controller and four phase signals $T_{1}, T_{2}, T_{3}$ and $T_{4}$ are

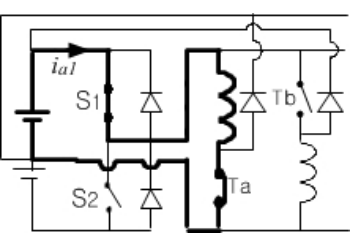

(a)

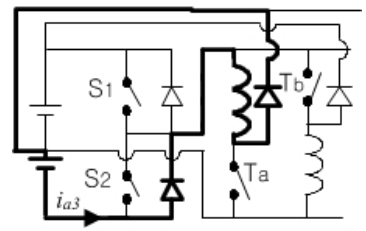

(c)

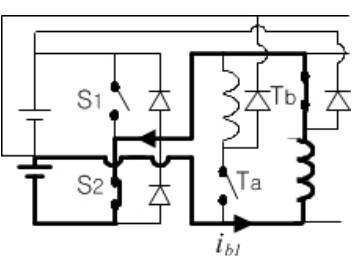

(e)

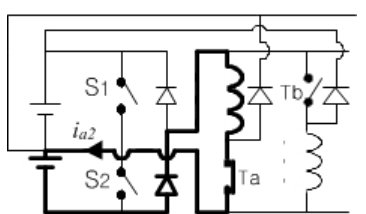

(b)

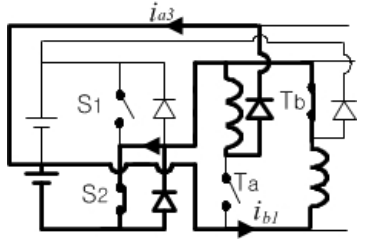

(d)

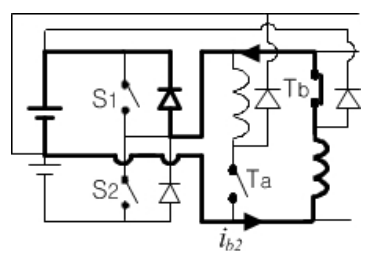

(f)

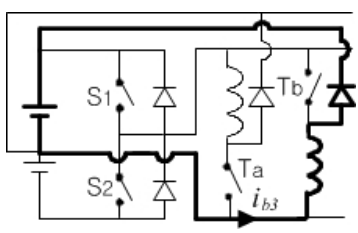

(g)

Fig. 5. Six operation modes in the SCHBI. (a) Mode I. (b) Mode II. (c) Mode III. (d) Overlapping mode. (e) Mode IV. (f) Mode V. (g) Mode VI.

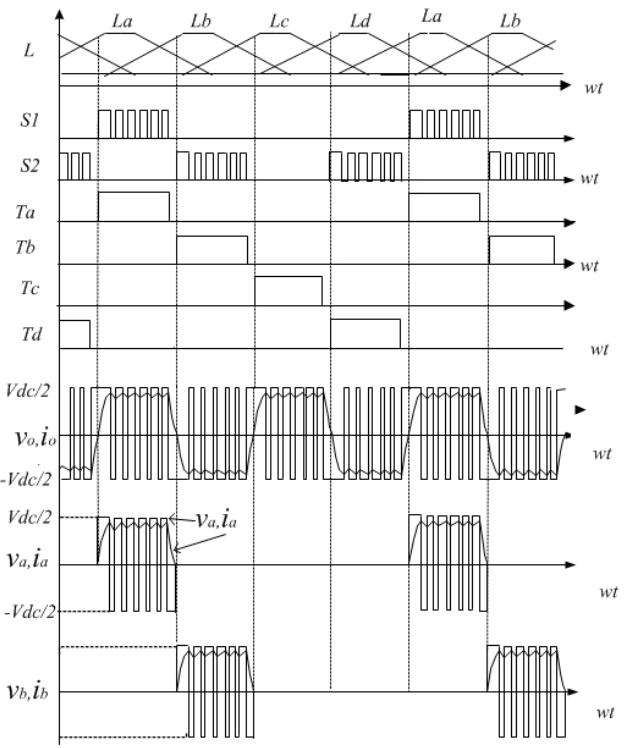

Fig. 6. Switching signals to an inverter and to a converter, and also output voltage, output current and phase voltage, and phase current by PWM controller in SCHBI. 


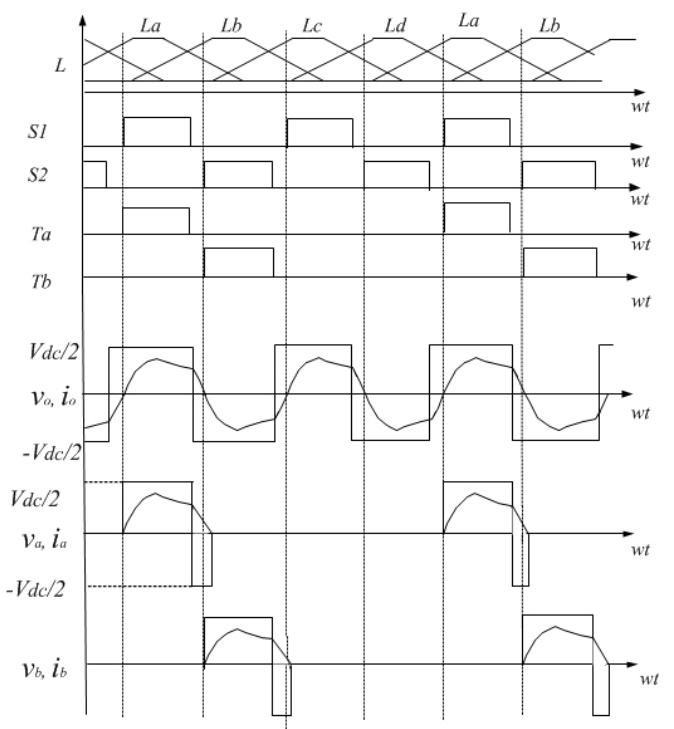

Fig. 7. Switching signals to an inverter and to a converter, and also output voltage, output current and phase voltage, and phase current by single pulse method in SCHBI.

controlled by a position sensor. Accordingly, the PWM output voltage and its output current at an inverter, and the phase voltages and phase currents at a converter are generated when an SCHBI operates according to two inverter signals and four phase signals. The output voltage at an inverter has a twolevel PWM waveform, and its output current approximates a trapezoidal waveform. Also, the phase voltage and its current for phase $\mathrm{A}$ and phase $\mathrm{C}$ at a converter are similar to the output waveforms at the inverter. However, the waveforms for the phase voltage and its current for phase $\mathrm{B}$ and phase $\mathrm{D}$ at a converter are opposite to those at an inverter.

Fig. 7 shows the switching signals and the waveforms for the voltages and currents when a SCHBI operates with the single-pulse method at high speed. Two inverter switching signals and four phase switching signals realize the PWM output voltage and output current of a SCHBI. From Fig. 6 and Fig. 7, the inverter switching signals and the phase switching signals should be synchronized with the turn on/off point of a phase switch. Two inverter signals and four phase signals realize the single pulse output voltage of the inverter, and the phase voltage. The phase current tail is suppressed by the negative voltage after the turn-off of a phase switch. This performance is similar to that of the split source converter in Fig. 3. In the split source converter, the speed of the SRM can only be controlled by means of the single pulse method, and it is impossible to chop the voltage using phase switches [1], [2]. However, with the proposed converter it is possible to chop the voltage using an inverter.

\section{Proposed Converter Topology Connected To a Single-Phase Full Bridge INVERTER}

Fig. 8 shows the SRM Converter connected to a singlephase Full Bridge Inverter (SCFBI). An SCFBI is a more advanced topology than an SCHBI though it needs more switches. The proposed SCFBI has eight basic operation modes as shown in Fig. 9.

\section{A. Operation Modes}

Mode I and mode V (magnetizing period): Fig. 9(a) shows mode $I$ when a phase switch $T_{a}$ is turned on, inverter switches $S_{1} \& S_{4}$ are ON, and $S_{2} \& S_{3}$ are OFF. The energy of the dc-link voltage $v(\theta)=V_{d c}$ is transferred to the phase winding A (or winding C). During mode I, the phase current $i_{a 1}$ can be obtained by solving (2) [2]:

$$
i_{a 1}(\theta)=\frac{V_{d c}-e}{R_{a}}\left[1-\exp \left(\frac{-\theta}{\omega_{m} \tau_{1}}\right)\right]+I_{\theta(O N n)} \exp \left(\frac{-\theta}{\omega_{m} \tau_{1}}\right)
$$

where, $I_{\theta(O N n)}$ is the initial value of $i_{a 1}$ at $\omega t=\theta_{O N n}$ and $e$ is the back-emf. Fig. 9(f) shows mode $\mathbf{V}$ when $\mathrm{T}_{\mathrm{b}}$ is turned on, $S_{2} \& S_{3}$ are $O N$, and $S_{1} \& S_{4}$ are OFF. This is the magnetizing circuit for a phase winding $\mathrm{B}$ (or winding $\mathrm{D}$ ).

Mode II and mode VI (freewheeling period): Fig. 9(b) shows mode II when $T_{a}$ is turned on, $S_{4}$ is ON and $S_{1}, S_{2}$ $\& S_{3}$ are OFF. At this time, the freewheeling circuit for the phase winding A (or winding $\mathrm{C}$ ) is formed through a inverter diode. The freewheeling phase current $i_{a 2}$ is decreased and is obtained by solving (2):

$$
i_{a 2}(\theta)=\frac{-e}{R_{a}}\left[1-\exp \left(\frac{-\theta}{\omega_{m} \tau_{1}}\right)\right]+I_{\theta(O F F n)} \exp \left(\frac{-\theta}{\omega_{m} \tau_{1}}\right)
$$

where, $I_{\theta(O F F n)}$ is the initial value of $i_{a 2}$ at $\omega t=\theta_{(O F F n)}$ and it is the maximum value during magnetizing period. Fig. $9(\mathrm{~g})$ shows mode VI when $T_{b}$ is turned on, $S_{3}$ is ON and $S_{1}, S_{2}$ $\& \mathrm{~S}_{4}$ are OFF. This is the freewheeling circuit for a phase winding $\mathrm{B}$ (or winding D).

Mode III and mode VII (first regenerating period): Fig. 10(c) shows mode III when $\mathrm{T}_{\mathrm{a}}$ is turned on and four inverter switches are OFF. The stored energy from a phase winding A (or winding C) returns to the dc-link voltage through the inverter terminal. Therefore, the first regenerating phase current $i_{a 3}$ decreases by the reverse dc-link voltage $v(\theta)=-V_{d c}$ and is obtained by:

$$
i_{a 3}(\theta)=\frac{-V_{d c}-e}{R_{a}}\left[1-\exp \left(\frac{-\theta}{\omega_{m} \tau_{1}}\right)\right]+I_{\theta(\text { OFF } n)} \exp \left(\frac{-\theta}{\omega_{m} \tau_{1}}\right)
$$

where, $I_{\theta(O F F n)}$ is the initial value of $i_{a 2}$ after a phase switch is turned off at $\omega t=\theta_{O F F n}$. Fig. 9(h) shows mode VII when $\mathrm{T}_{\mathrm{b}}$ is turned on and four inverter switches are OFF. This is first regenerating circuit for a phase winding B (or winding D).

Mode IV and mode VIII (second regenerating period): Fig. 9(d) shows mode IV when $T_{a}$ is turned off and four inverter switches are OFF. The circuit of mode IV is the same as the regenerating circuit in mode III. The stored energy from a phase winding $\mathrm{A}$ (or winding $\mathrm{C}$ ) returns to the dclink voltage through the regenerating path. The current tail is quickly suppressed by the reverse dc-link voltage $v(\theta)=-V_{d c}$ after $T_{a}$ is turned off, and it can be expressed as (7). Fig. 9(i) shows mode VIII when $T_{b}$ is turned off and four inverter switches are OFF. This is the second regenerating circuit for a phase winding $\mathrm{B}$ (or winding $\mathrm{D}$ ).

Overlapping mode: Fig. 9(e) shows the overlapping mode (between mode IV and mode V, or between mode VIII and mode I) where the phase current flows simultaneously in the 


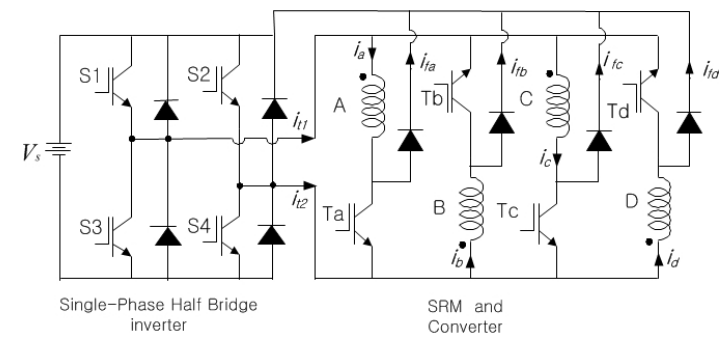

Fig. 8. The proposed SRM converter connected to a full bridge inverter (SCFBI ; $n=4)$.

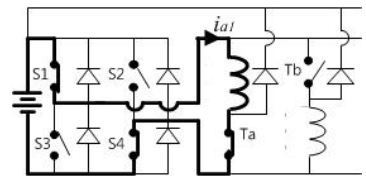

(a)

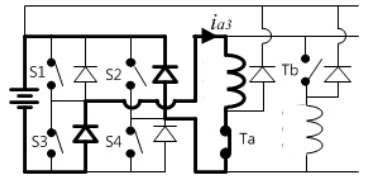

(c)

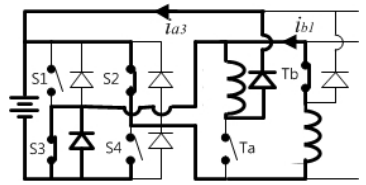

(e)

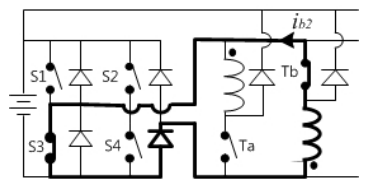

(g)

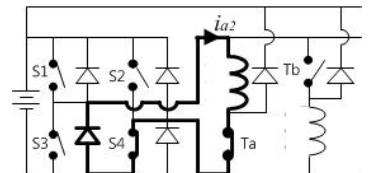

(b)

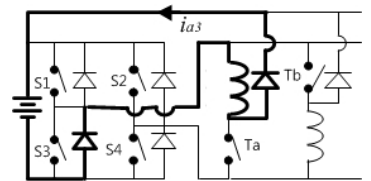

(d)

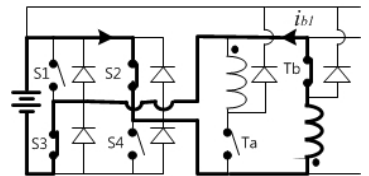

(f)

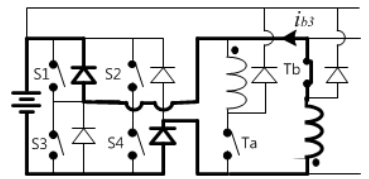

(h)

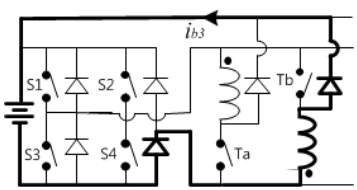

(i)

Fig. 9. Eight operation modes in SCFBI. (a) Mode I. (b) Mode II. (c) Mode III. (d) Mode IV. (e) Overlapping mode. (f) Mode V. (g) Mode VI. (h) Mode VII. (i) Mode VIII.

phase windings $\mathrm{A}$ and $\mathrm{B}$ (or windings $\mathrm{B}$ and $\mathrm{C}$, windings $\mathrm{C}$ and $\mathrm{D}$, or windings $\mathrm{D}$ and $\mathrm{A})$. When the off-going phase switch $T_{b}$ is turned on, $S_{2}$ and $S_{3}$ are ON before the current tail of $i_{a}$ is decayed, the energy of the dc-link voltage is transferred to the phase winding $\mathrm{B}$, and the stored energy from the phase winding A continues to return to the dc-link voltage. However, the overlapping mode is omitted if mode $\mathbf{V}$ begins after the current tail in mode IV is decayed. Mode I \& mode $\mathbf{V}$ and mode II \& mode VI are used during the period of the dwell angle, but mode IV \& mode VIII and overlapping mode are used after the turn-off of a phase switch.

\section{B. Waveforms}

Fig. 10 shows the switching signals and the waveforms for the voltages and currents when a SCFBI operates according to the PWM method. Four switching signals at an inverter are regulated by a PWM controller and four phase switching signals at an converter are controlled by a position sensor. The PWM output voltage and its output current at an inverter, and the phase voltages and phase currents at a converter are generated when a SCFBI operates according to four inverter signals and four phase signals. The output voltage at an inverter has the three-level PWM waveform.

Fig. 11 shows the switching signals and the waveforms for the voltages and currents when a SCFBI operates by the single-pulse method. Four inverter switching signals and four phase switching signals realize the output voltage and current of a SCFBI. The output voltage and the output current at an inverter, and the phase voltage and phase currents at a converter is when an SCFBI operates by the switching signals. From the figure, it can be seen that the current tail is suppressed by the negative voltage after the turn-off of a phase switch. The output voltage and its output currents are similar to those of an SCHBI.

\section{Comparisions of the Proposed Topologies AND CONVENTIONAL TOPOLOGIES}

Based on the above expressions about conventional topologies and the proposed topologies, performances and comparisons are presented in this chapter.

\section{A. Advantages and disadvantages of the proposed topologies.}

\section{1) Advantages:}

- The proposed topologies considerably reduce the switching losses in the phase switches, the motor core loss, and the acoustic noise of the motor when compared to drive systems using the fixed dc-link.

- The proposed topologies maintain high efficiency because the stored energy returns to the dc-link after the turn-off of the power switches. Therefore, the characteristics of the proposed topologies approach those of a split source topology, an asymmetric topology, etc.

- The proposed topologies achieve the regenerating characteristic which is not includes in the "drive system by dc-chopper."

- Dead time compensation can be neglected in an inverter of the proposed topologies, and the inverter switching signals should be synchronized with the phase switching signals. Therefore, the software of the proposed topologies is relatively simple.

- Voltage chopping is possible by means of an inverter in an SCHBI, while it is impossible using the phase switches in a split source converter. Also, an inverter in the proposed topologies acts as peak-current limiters if the transient current tends to exceed the maximum value under heavy loads.

- The characteristics of SCFBI topology are similar to those of an asymmetric bridge topology involving a dc chopper. 


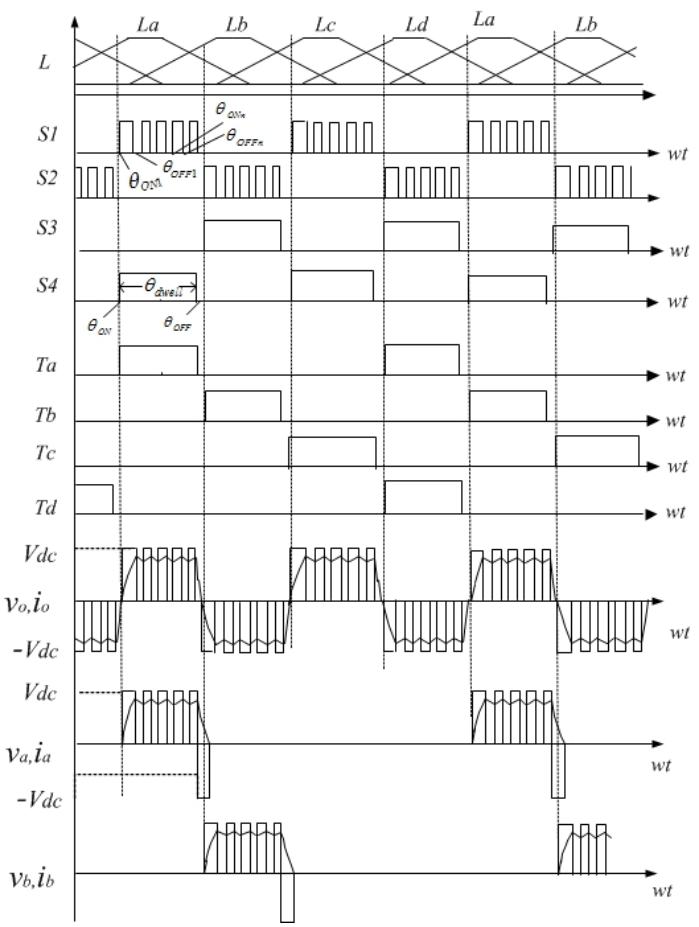

Fig. 10. Switching signals to an inverter and to a converter, and also output voltage, output current and phase voltage, and phase current by PWM controller in SCFBI.

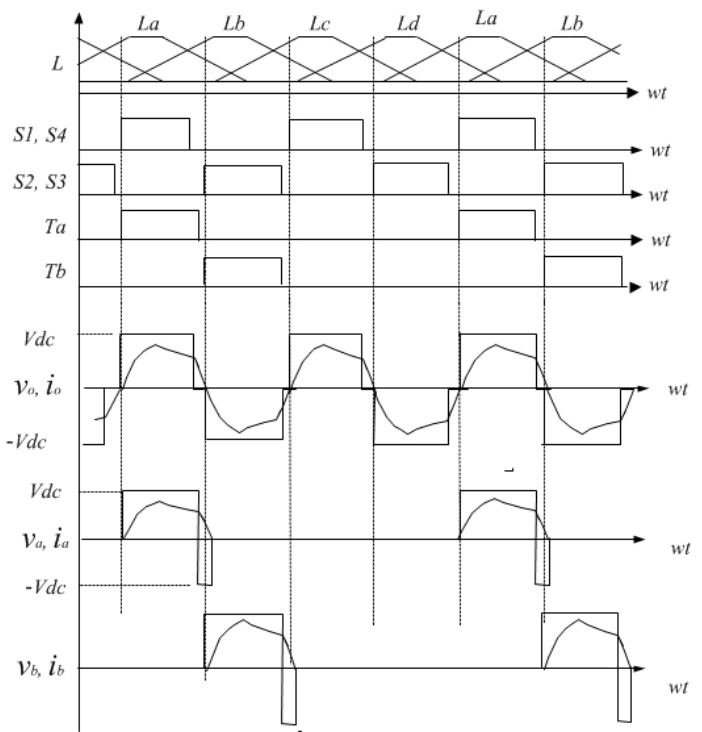

Fig. 11. Switching signals to an inverter and to a converter, and also output voltage, output current and phase voltage, and phase current by single-pulse method in SCFBI.

Furthermore, this is accomplished with decreasing the total numbers of switches in an SCFBI when compared to the asymmetric bridge topology (case of an 8/6 SRM). Moreover, the total number of switches in an SCFBI is less than those of the asymmetric bridge topology relatively according to the increase of poles more and more. Also, as cheaper power switch modules with higher quality are developed, the manufacturing cost of the proposed SCFBI will be decreased.

\section{2) Disadvantages:}

- The proposed topology is limited to SRMs with an even
TABLE I

THE PARAMETERS AND SPECIFICATIONS OF THE MODEL SRM

\begin{tabular}{|c|c||c|c|}
\hline $\begin{array}{c}\text { phase inductances at } \\
\text { aligned }\end{array}$ & $88.3 \mathrm{mH}$ & $\begin{array}{c}\text { phase inductances at } \\
\text { naligned }\end{array}$ & $10.6 \mathrm{mH}$ \\
\hline Stator/Rotor poles & $8 / 6$ & Rated power & $1.5 \mathrm{hp}$ \\
\hline Rated voltage & $100 \mathrm{~V}$ & Rated current & $12 \mathrm{~A}$ \\
\hline Stator winding resistor & $0.12 \Omega$ & & \\
\hline
\end{tabular}

number of stator phases because the proposed SRM converter is similar to a split source converter.

- Implementing the "drive system by an inverter" is more complex than that of the conventional "drive system by dc chopper".

\section{B. Comparison of the two proposed topologies}

- The power circuit of an SCHBI is simpler than that of an SCFBI because the SCHBI has two power switches while the SCFBI has four power switches. Therefore, the SCHBI is suitable for fractional horsepower SRM drives.

- An inverter in an SCFBI requires one capacitor to maintain the GND at midpoint, while an SCHBI requires two capacitors to maintain a split voltage source. One dclink capacitor in an SCFBI makes a SRM drive stable. Also, an inverter in an SCFBI supplies three-level output voltages $\left(V_{d c}, 0,-V_{d c}\right)$ to the converter while the inverter in an SCHBI supplies two-level output voltages $\left(V_{d c} / 2,-V_{d c} / 2\right)$ to the converter. At this time, the voltage range of an SCFBI is twice that of an SCHBI. Also, the freewheeling modes are possible with an SCFBI while they are impossible with an SCHBI.

\section{Simulation RESULTS}

Since the proposed topologies have not been previously implemented in any other studies, the simulation tests were conducted on a model SRM through MATLAB. The parameters and specifications for a model SRM are given in Table I.

The operation modes for the two proposed topologies are explained in the foregoing chapters. The effect of a current tail for the output current from the inverter is ignored there. Accordingly, the simulations of the currents at an inverter and a converter need to be analyzed while considering the effect of the current tail. For the simulation tests an SCFBI is used as a model topology.

Fig. 12 shows the simulated waveforms of the inductance profile for this simulation $L$, the output voltage $V_{o_{-} i n v}$, the current tail $i_{f a}, i_{f c}, i_{f b}, \& i_{f d}$ and the two output currents $i_{t 1} \& i_{t 2}$ for the inverter when a SCFBI operates according to the single-pulse method. The turn-on angle is fixed at $-6^{\circ}$ and the turn-off angle is fixed at $7^{\circ}$ for this simulation. The simulated waveform for the output voltage $V_{o \_} i n v$ is a threelevel PWM waveform. The GND in $V_{o_{-} i n v}$ is built up while all of the switches are turned off with mode IV and mode VIII, as is shown in Fig. 11. The current tails $i_{f a}$ and $i_{f c}$ of phases $\mathrm{A}$ and $\mathrm{C}$ flow through the regenerating pass in mode IV as do the current tails $i_{f b}$ and $i_{f d}$ for phases B and D in mode VIII. The output current $i_{t 1}$ at the up-line of the energy transferring pass, and the output current $i_{t 2}$ at a down-line between an inverter and a converter are shown in Fig. 9. It is observed 


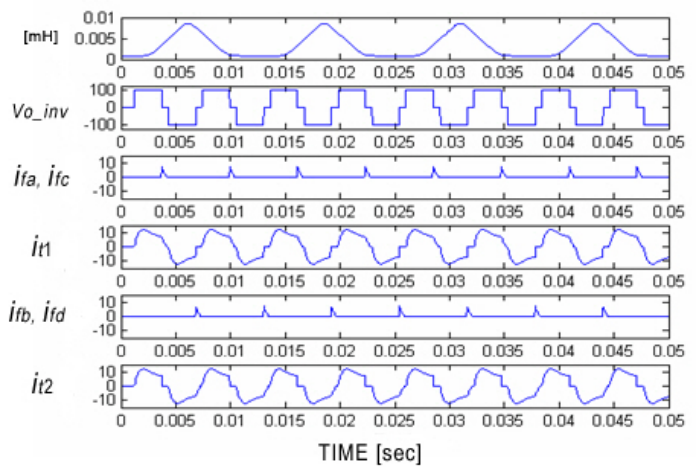

Fig. 12. Simulated waveforms for inductance profile $L$, output voltage $V_{o_{-} i n v}$, current tail $i_{f a}, i_{f c}$, output current $i_{t 1}$ at the inverter, current tail $i_{f b}, i_{f d}$, and output current $i_{t 2}$ at the inverter of SCFBI by single-pulse method.

that the current tails $i_{f a}$ and $i_{f c}$ of phases A and $\mathrm{C}$ affect the output current $i_{t 1}$, while $i_{f b}$ and $i_{f d}$ do not affect $i_{t 1}$. Also, the current tails $i_{f b}$ and $i_{f d}$ affect the output current $i_{t 2}$, while $i_{f a}$ and $i_{f c}$ do not affect $i_{t 2}$. Accordingly, the $i_{f a}$ and $i_{f c}$ are involved in $i_{t 1}$ at an inverter, while $i_{f b}$ and $i_{f d}$ are involved in $i_{t 2}$.

Fig. 13 shows the simulated waveforms of the phase A voltage, the phase A current and the phase B current of a converter when a SCFBI operates according to the single pulse method under the same conditions as shown in Fig. 12. The positive phase voltage changes to a negative voltage quickly when the phase switch is turned off, and the negative voltage disappears as soon as the phase current is decayed. Also, the waveform of the phase B current is equal to that of the phase A current after the stroke angle.

Fig. 14 shows the simulated waveforms for the inductance profile, the output voltage at an inverter, the current tail, and the output current at an inverter when a SCFBI operates according to the PWM method using the hysteresis band. The turn-on angle is fixed at $-4^{\circ}$, while the turn-off angle is fixed at $9^{\circ}$ for this simulation. In addition, the output current is fixed at $7 \mathrm{~A}$ for chopping. The output PWM voltage $V_{o \_i n v}$ has three level waveforms, and $i_{f a}$ and $i_{f c}$ flow in the regenerating pass after a phase switch is turned off. At this time, $i_{f a}$ and $i_{f c}$ are involved in the output current $i_{t 1}$ (up-line) of the inverter. The output current is similar to a trapezoid waveform and it is damaged by the current tail.

Fig. 15 shows the simulated waveforms for the phase voltage and the two phase currents at the converter when an SCFBI operates according to the PWM method under the same conditions as in Fig. 13. The phase voltage and the phase current are generated when the phase switch is turned on or off. After the stroke angle, the phase current waveform is the same as the next phase current waveform.

\section{EXPERIMENTAL RESULTS}

An experimental setup has been developed to verify the theoretical development and the simulation results. The proposed topologies were implemented using a low cost TMS320C2407 DSP. The test circuit for the proposed topology was built and evaluated using an 8/6, $1.5 \mathrm{hp} \mathrm{SRM.} \mathrm{The} \mathrm{dc-link} \mathrm{voltage} \mathrm{was}$ $60 \mathrm{~V}$, and the chopping frequency at the inverter was $12 \mathrm{kHz}$.

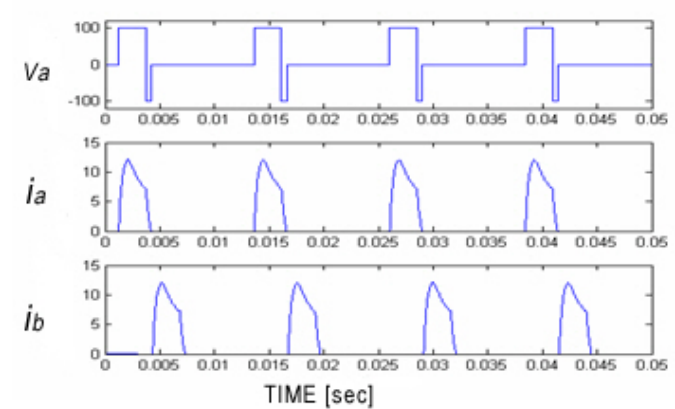

Fig. 13. Simulated waveforms for phase voltage, and two phase currents at the converter of SCFBI by single-pulse method.

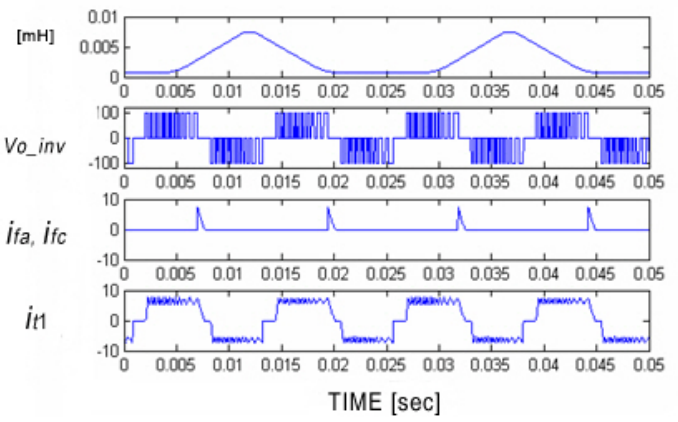

Fig. 14. Simulated waveforms for inductance profile, output voltage, current tail $i_{f a}, i_{f c}$, and output current $i_{t 1}$ at the inverter of SCFBI by PWM method.

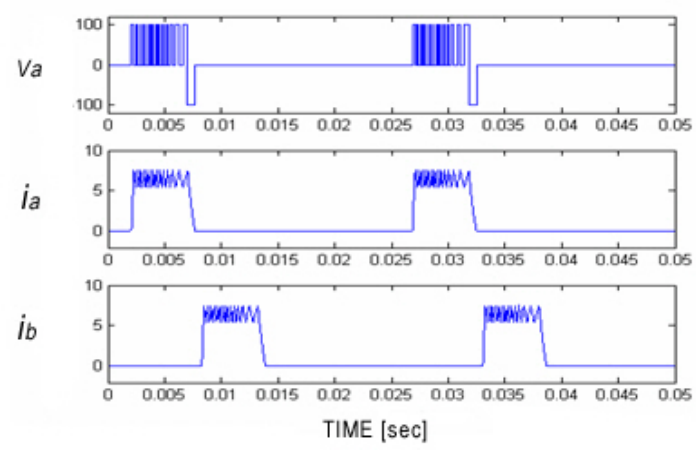

Fig. 15. Simulated waveforms for phase voltage and two phase currents at the converter of SCFBI by PWM method.

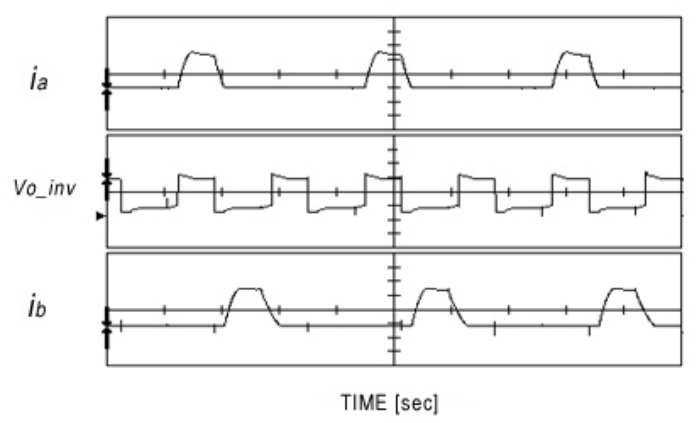

Fig. 16. Experimental waveforms for current of phase A, output voltage at the inverter, and current of phase B of SCHBI $(2 \mathrm{mS} / \mathrm{div}, 5 \mathrm{~A} / \mathrm{div}, 50 \mathrm{~V} / \mathrm{div})$. 


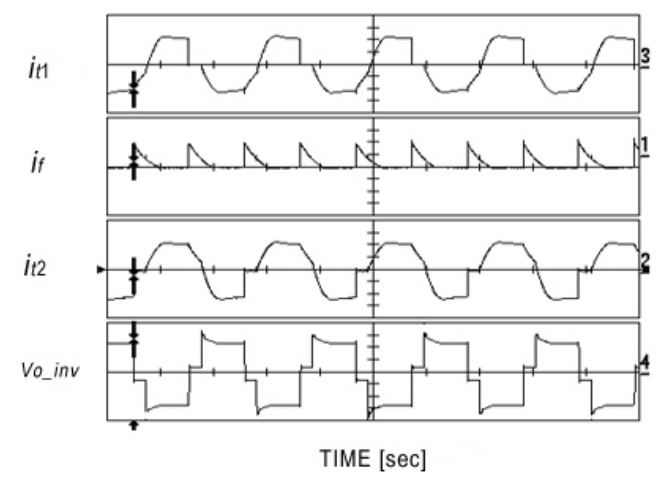

Fig. 17. Experimental waveforms for output current at up-line, current tail, output current at down-line, and output voltage at an inverter of $\operatorname{SCFBI}(2$ $\mathrm{mS} / \mathrm{div}, 5 \mathrm{~A} / \mathrm{div}, 100 \mathrm{~V} / \mathrm{div})$

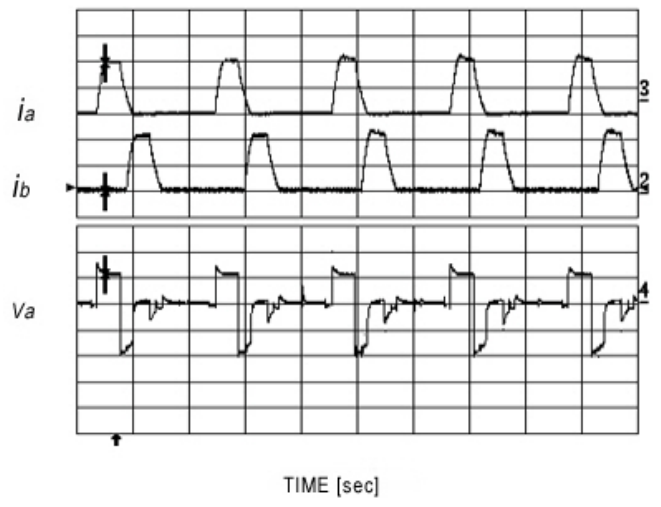

Fig. 18. Experimental waveforms for current of phase A and phase B, voltage of phase A at the converter of SCFBI $(2 \mathrm{mS} / \mathrm{div}, 5 \mathrm{~A} / \mathrm{div}, 50 \mathrm{~V} / \mathrm{div})$.

Fig. 16 shows the experimental waveforms for two phase currents at the converter and the output voltage at the inverter when an SCHBI operates using the single-phase method. The turn-on angle was fixed at $-6^{\circ}$ and the turn-off was fixed at $7^{\circ}$. Unlike the experimental speed of a SCFBI, the motor speed was measured at $1818 \mathrm{rpm}$. It is observed that the experimental waveforms of the phase current are equal to the next one after the stroke angle. The experimental output voltage has two level waveforms, as explained in Fig. 7.

Fig. 17 shows the experimental waveforms of the output current, the current tail and the output voltage when an SCFBI operates by means of the single-phase method under same conditions as in Fig. 16. The current tail affects the two output currents $i_{t 1}$ (up-line) and $i_{t 2}$ (down-line) of the inverter.The output voltage of the inverter has a three-level waveform like the simulated waveform in Fig. 12.

Fig. 18 shows the experimental waveforms of the two phase currents and the output voltage of the converter when an SCFBI operates by means of the single-phase method under the same conditions as those shown in Fig. 16. At this time, the motor speed was measured at $2857 \mathrm{rpm}$. Accordingly, the motor speed in an SCFBI will be faster than that in an SCHBI because the inverter of an SCFBI makes a higher output voltage when compared to an SCHBI. Also, the experimental waveforms of the phase current are equal to the next one after the stroke angle. These results are similar to the simulated result in Fig. 13.

Fig. 19 shows the experimental PWM waveforms of the

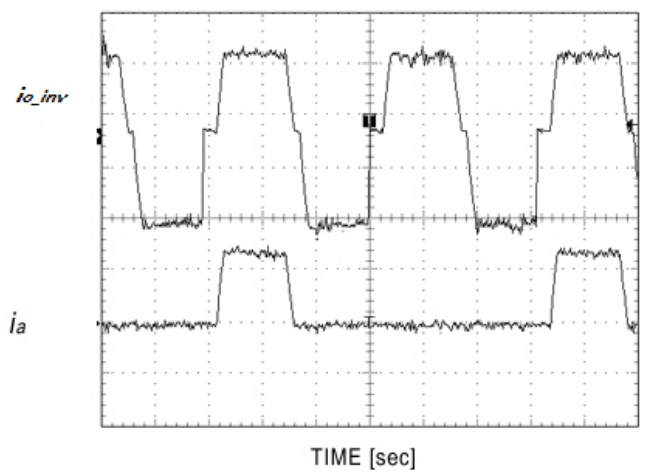

Fig. 19. Experimental PWM waveforms for output current of inverter and phase current at the converter of $\operatorname{SCHBI}(2 \mathrm{mS} /$ div, $5 \mathrm{~A} / \mathrm{div})$.

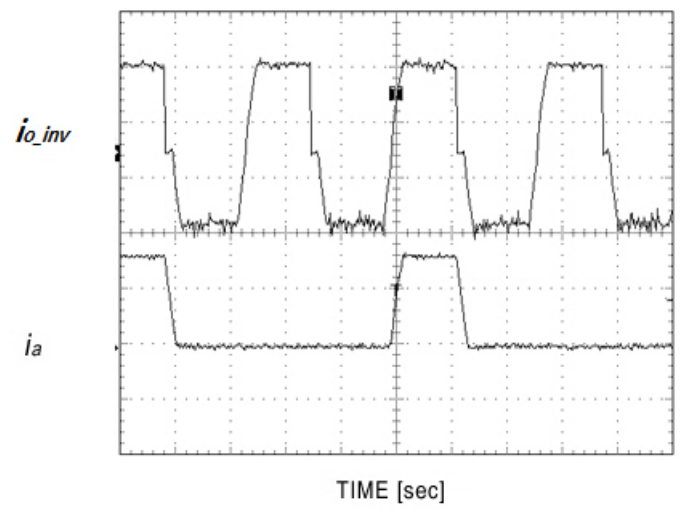

Fig. 20. Experimental PWM waveforms for output current of inverter and phase current at the converter of $\mathrm{SCFBI}(2 \mathrm{mS} / \mathrm{div}, 5 \mathrm{~A} / \mathrm{div})$.

output current of an inverter and the phase current at a converter when an SCHBI operates by means of a PWM controller. The turn-on angle was fixed at $-5^{\circ}$, the turn-off angle is fixed at $7^{\circ}$, and the command phase current was $7 \mathrm{~A}$. At this time, the motor speed was measured at about $963 \mathrm{rpm}$.

Fig. 20 shows the experimental PWM waveforms of the output current of an inverter and the phase current of a converter when an SCFBI operates by means of a PWM controller under the same conditions as those of Fig. 19. At this time, the motor speed was measured at about $1149 \mathrm{rpm}$. From Fig. 19 and Fig. 20, it is observed that output current approaches a trapezoidal waveform, and that it is affected by the current tail.

\section{CONCLUSION}

This paper proposes a novel drive system using a variable dc-link voltage, which is composed of a proposed SRM converter and a single-phase inverter. A typical single-phase inverter can generate a variable dc-link voltage. In this paper, the two topologies for an SCHBI and an SCFBI are proposed according to the power circuit of the inverter. The proposed SRM converter with one switch per a phase is simple and it can achieve high efficiency.

The motor torque or the phase current is controlled by means of a PWM controller at the inverter of the proposed topology, while voltage chopping is impossible in a split source converter. Also, the inverter acts as a peak-current limiter if the transient current tends to exceed its maximum 
value under heavy loads. The turn-on/off points of the phase switches can be regulated by a position sensor at the proposed SRM converter. The hardware and software for an SCHBI are simpler than those of an SCFBI. Therefore, an SCHBI will be suitable for fractional horsepower SRM drives. An SCFBI will be suitable for medium horsepower SRM drives though the hardware for an SCFBI is more complex than that of an SCHBI because the performance of the full-bridge inverter of an SCFBI is superior to that of a half bridge inverter.

Six basic operation modes for an SCHBI and eight basic operation modes for an SCFBI are analyzed by means of equations. The overlapping mode after the turn-off of the phase switch is explained in detail. The output currents of an inverter and the phase currents of a converter are simulated considering the effect of the current tail. They are confirmed by experimental results.

\section{ACKNOWLEDGMENT}

This research was supported by an Academic Research grant from Hoseo University, Korea, in 2006 (R-2005-7-139).

\section{REFERENCES}

[1] T. J. E. Miller, Switched Reluctance Motors and Their Control. Oxford, England: Oxford Press, 1993.

[2] R. Krishnan, Switched Reluctance Motor Drives,: Modeling, Simulation, Analysis, Design, and Applications. New York CRC Press, 2001.

[3] J. Kim and R. Krishnan, "Novel two switch based switched reluctance motor drive for low cost high volume applications," IEEE Trans. Ind. Appl., Vol. 45, No. 4, pp. 1241-1248, Jul. 2009.

[4] H. S. Lim, R. Krishnan, and N. S. Lobo, "Design and control of a linear propulsion system for an elevator using linear switched reluctance motor drives," IEEE Trans. Ind. Electron., Vol. 55, No.2, pp. 534-542, Feb. 2008.
[5] G.-H. Rim and W.-H Kim, " A novel converter topology for switched reluctance motor drives improving efficiency and simplifying control strategy," in Proc. IEEE PESC'94, Vol. 1, pp.937-947, 1994.

[6] P. Pillay, "Modeling and performance of a SRM drive with improve ride-through capacity," IEEE Trans. Energy Convers., Vol. 16, No. 2, pp.165-173, Jun. 2001.

[7] K. Y. Cho, and J. Y. Lim, "Power converter circuit for a switched reluctance motor using a flyback transformer," IEE Pro., Electr Power Appl., Vol. 150, No. 1, pp. 88-96. Jan. 2003.

[8] Y. Saleem and T. Izhar, "Control of torque in switched reluctance motor," in conf. Rec. Int. Con. Elec. Eng. Annu. Meeting, Mar. 2008.

[9] D. Panda and V. Ramanarayanan, "Reduced acoustic noise variable dcbus votage-based sensorless switched reluctance motor drive for HVAC applications," IEEE Trans. Ind. Electron., Vol. 54, No. 4, pp.2065-2078, Aug. 2008.

[10] J. Y. Chai, Y. W. Lin, and C. M. Liaw, ” Comparative study of switching controls in vibration and acoustic noise reductions for switched reluctance motor," IEE Proc.-Electr. Power Appl., Vol. 153, No. 3, pp. 348360, May 2006.

[11] J. Li, X. Song, and Y. Cho, "Comparison of $12 / 8$ and 6/4 switched reluctance motor: noise and vibration aspects IEEE Trans. Mag., Vol. 44, No. 11, pp.4131-4134, Nov. 2008.

[12] X. D. Xue, K. W. E. Cheng, and S. L. Ho, "Study of power factor in SRM drives under current hysteresis chopping control," in $40^{\text {th }}$ conf. Rec. IEEE IAS Annu. Meeting, pp.2734 -2740, 2005.

[13] I. Kioskeridis and C. Mademlis, "Maximum efficiency in single-pulse controlled switched reluctance motor drives," IEEE Trans. Energy Convers., Vol. 20, No. 4, pp.809-817, Dec. 2005.

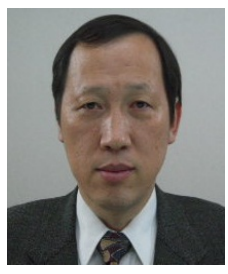

Do-Hyun Jang was born in Cheonan, Choongnam, Korea, in 1956. He received his B.S. in Electrical Engineering from Hanyang University, Seoul, Korea, in 1976, and his M.S. and Ph.D. in Electrical Engineering from Seoul National University, Seoul, Korea, in 1982 and 1989 , respectively. Since 1985 , he has been with the Department of Electrical Engineering, Faculty of Engineering, Hoseo University, Asan, Korea, where he is currently a Professor. His research interests include the advanced control of adjustable speed control for ac machines and SRMs, and PWM techniques for inverters. 